Running Head: WHO IS MORE LIKELY TO INFLUENCE OTHERS?

Who is more likely to influence others? A value-based approach to pro-environmental social influence behavior

Andrea Kis ${ }^{1}$, Mark Verschoor ${ }^{2}$, Rebecca J. Sargisson ${ }^{2}$

${ }^{1}$ Corresponding author: Eindhoven University of Technology, Netherlands

${ }^{2}$ Department of Psychology, University of Groningen, The Netherlands 


\begin{abstract}
Biospheric values can promote, and egoistic values inhibit, a broad range of proenvironmental behaviors. However, people who strongly endorse egoistic values might undertake pro-environmental behavior involving attempts to influence others. We used a questionnaire to assess the relationship between values and the likelihood that with 193 students will attempt to influence their housemates to engage in pro-environmental behavior. To measure this type of influence behavior, we developed and used the Environmental Social Influence Behavior (E-SIB) questionnaire. Both biospheric and egoistic values promoted influence behaviors. Biospheric values more strongly predicted the likelihood of socialinfluence actions as egoistic values decreased, except when egoistic values were high. We discuss the connections between values and social-influence behaviors, and current knowledge on the role of egoistic values in environmental actions.
\end{abstract}

Keywords: biospheric values, egoistic values, household energy conservation, proenvironmental behavior, social influence behavior

Conceptualization, A.K. and M.V.; Data curation A.K. and M.V.; Formal Analysis A.K. and R.S.; Investigation, A.K.; Methodology A.K., M.V., and R.S.; Project administration R.S.; Supervision R.S.; Visualization A.K.; Writing - original draft A.K. and R.S.; Writing - review \& editing A.K., R.S. and M.V. 


\section{Who is more likely to influence others? A value-based approach to pro- environmental social influence behavior}

Households in Europe consume approximately $30 \%$ of the total energy supply of the EU (European Environment Agency, 2018) and are responsible for 25\% of greenhouse gas emissions of the total emissions of EU countries (European Environment Agency, 2012). Furthermore, in the Netherlands, the combined indirect and direct energy requirements of households constitute about $80 \%$ of total energy flows of the country (Benders, Kok, Moll, Wiersma, \& Noorman, 2006). As these energy requirements continue to rise, and related environmental problems are directly caused by human behavior (IPCC, 2018), they can be reduced if people more consistently engage in pro-environmental actions, behaviors that harm the natural environment as little as possible, enhance environmental quality, or even benefit the environment (Larson, Stedman, Cooper, \& Decker, 2015). Although industry and business use large amounts of energy too, households use a substantial amount of energy and behavior change at the household level is also important. Household energy-use reduction could be accomplished by better understanding consumer behaviors and the underlying psychological variables affecting pro-environmental behavior (Abrahamse \& Steg, 2009), such as values (Steg \& de Groot, 2018).

\section{Values and behaviors}

Values are beliefs related to preferable end states or behaviors, which surpass distinct situations, guide assessment and selection of behavior and events, and are ordered based on subjective significance (Schwartz, 1992). Values affect behavior directly or indirectly and could be mediated by behavior-specific attitudes, norms, or beliefs (Steg \& de Groot, 2018). Values are especially important constructs in terms of understanding pro-environmental behaviors as there are relatively fewer values than other related variables (e.g., norms or attitudes), values are abstract and hence allow for prediction in a wide variety of situations, 
and pro-environmental values have been found to have a causal influence on sustainable behaviors (Steg \& de Groot, 2018).

Based on the self-enhancement to self-transcendence dimension of the original value typology proposed by Schwartz (1992), four values have been found to be relevant in predicting pro-environmental behaviors (de Groot \& Steg, 2008; Steg, Perlaviciute, van der Werff, \& Lurvink, 2014). Distinctions between biospheric and altruistic values within the self-transcendence dimension (i.e., values stressing the interests of others) and of egoistic and hedonic values in the self-enhancement dimension (i.e., values related to self-interest, achievement, and power) are important predictors of pro-environmental attitudes, norms, and behavior (Steg \& de Groot, 2018). Correspondingly, biospheric values represent concerns for the natural environment and the quality of nature, while altruistic values reflect a concern for the well-being of others and social justice. Egoistic values express a concern for power and personal status, whereas hedonic values reflect concerns for personal enjoyment, pleasure, and reducing effort (de Groot \& Steg, 2008; Steg et al., 2014).

Values are thought to affect behavior directly or indirectly via the mediation of behavior-specific attitudes, norms, or beliefs (Steg \& de Groot, 2018). Empirical studies and theoretical approaches emphasize the positive influence of biospheric values on an array of pro-environmental behaviors, including recycling (Schultz \& Zelezny, 1998), sustainable transport mode choice (Lind, Nordfjærn, Jørgensen, \& Rundmo, 2015), and energy conservation behavior (Steg, Dreijerink, \& Abrahamse, 2005; van der Werff \& Steg, 2016). Strong egoistic and hedonic values typically inhibit pro-environmental actions (Steg \& de Groot, 2018) as they reflect self-enhancement concerns instead of concerns for the environment and many pro-environmental behaviors might be perceived to have disadvantages for the individual (Nathan, 2016). 
Recent findings, however, point self-enhancing reasons as a basis of proenvironmental behaviors: Actions benefiting the environment might develop based on selfinterest (e.g., being healthy or gaining social status) or without individuals knowing that they are behaving pro-environmentally (Dominicis, Schultz, \& Bonaiuto, 2017). Furthermore, some authors raised the need for a further inspection of relationships between egoistic values and a wider range of actions that could be considered more beneficial for individuals with stronger self-enhancement values as related findings seem to be scarce (Bouman, Steg, \& Kiers, 2018).

\section{Social influence as a type of pro-environmental behavior}

Social influence is one of the most widely used fundamental concepts within social psychology (Hogg \& Cooper, 2007). Accordingly, it has several interpretations. Broadly, social influence is a process of one person, group, or class influencing other persons, groups, or classes by attempting to change their values, attitudes, opinions, or behaviors (Reber \& Reber, 2001). A more specific interpretation is that social influence occurs whenever the thoughts, feelings, or actions of an individual are influenced by groups or other people (Forgas \& Williams, 2001).

Although social influence behavior directed at urging others to act more environmentally friendly is relevant for pro-environmental actions, as of now, the literature on how social influence could be a specific type of pro-environmental behavior is fragmented, and applications of social influence theory within green household behavior are especially scarce (Goldsmith \& Goldsmith, 2011). Indeed, some researchers argue that although there is a wide variety of studies focusing on the importance of environmentally friendly actions, the terminology used to describe, and the operationalization of, proenvironmental behavior varies greatly (Larson et al., 2015). 
One commonly recognized categorization of pro-environmental behavior is based on a distinction between private-sphere and public-sphere behaviors (Larson et al., 2015; Sloot, Kutlaca, Medugorac, \& Carman, 2018; Stern, 2000). Private sphere behaviors occur in private spaces and entail behaviors such as recycling or purchasing sustainable products (Nakagawa, Mori, Nishimura, \& Hayashi, 2019). Public sphere behaviors are more organized and social, for example, pro-environmental lobbying or signing petitions (Nakagawa et al., 2019). In some studies, public sphere behaviors are sometimes described similarly to social influence and entails behaviors of influencing others (e.g., Sloot et al., 2018), yet research on public-sphere behavior seems to be limited thus far (Lange \& Dewitte, 2019; Truelove \& Gillis, 2018). Even when deliberated, most authors do not differentiate between large-scale public-sphere actions such as political activism directed at influencing policy makers or groups of individuals, and smaller-scale actions encouraging peers or family members to act more pro-environmentally.

Larson and colleagues (2015) posit that pro-environmental behaviors contain four main domains. Firstly, conservation lifestyle behaviors, defined as simple acts revolving around conservation (e.g., household energy conservation or recycling). Second, social environmentalism, described as social engagement and encouragement targeted at peers to educate them about environmental issues (e.g., participation in environmental groups, informal information exchange with peers). Third, environmental citizenship behaviors referring to actions conducted affecting the public sphere (e.g., donating to pro-environmental causes, voting or signing petitions). Fourth, land stewardship related to ecosystem-level protection actions (e.g., habitat management, data collection for environmental inventories). Within this distinction, social environmentalism seems to be the most related to social influence aiming at urging peers to act more environmentally friendly.

\section{Values and social influence behavior}


In sum, studies on how values influence pro-environmental actions have mostly used private behavior (e.g., energy conservation behaviors) and rarely considered actions directed at influencing other individuals (Sloot et al., 2018). Correspondingly, researchers have explored the underlying mechanisms of being influenced by others, yet knowledge on the goals served by influencing others seems to be scarce (Bourgeois, Sommer, \& Bruno, 2009), especially in the environmental psychology literature. Although there seems to be a lack of a single line of research, several different discussions are emerging in parallel on the importance of urging others to act pro-environmentally.

Other-directed behaviors. Biospheric values are assumed to relate to any actions aimed at benefiting the environment (de Groot \& Steg, 2008). Hence, we expect biospheric values to influence the behavior of urging others to act more environmentally friendly. Sloot and colleagues (2018) used this argument when exploring the possible connections between all four value types and other-directed behaviors, which they defined as actions pursuing broader societal change (in this case, normative public protests, civil disobedience, proenvironmental lobbying) by the means of influencing others. Contrary to their expectations, relationships between such actions and biospheric values were not found. However, they attributed this result to the specific sample of environmental activists used and the nature of actions studied - they found that as altruistic values better reflected needs for influencing systemic problems, altruistic values were more relevant for influence actions connected to political activism.

Yet, Sloot and colleagues (2018) also found support for the role of egoistic values. They found a positive relationship between pro-environmental lobbying and egoistic values and argued that this connection could be attributed to sub-values within the egoistic value scale, such as having influence over others. Egoistic values are usually measured with five sub-items, namely social power which relates to a need for controlling others and dominance, 
wealth reflecting needs for material possessions and money, authority, emphasizing a right to command or lead, influence linked to a need to impact other people or events, and ambition, reflecting concerns for working hard (de Groot \& Steg, 2008). Sloot et al. (2018) reasoned that lobbying does not reflect a need for money or dominance, but could be based on individuals striving to influence power-holders to support their cause.

Social influence actions. The role of egoistic values (or at least sub-egoistic values, i.e., social power, wealth, authority, influence) is further supported by a broader approach to social influence. Bourgeois and colleagues (2009) propose that the goals served by performing social influence actions (i.e., urging others to do something) could have a psychological basis. Among other goals, they list a need for control over others and a need for a meaningful existence, including having a lasting influence on other people.

Social environmentalism. A recent line of research addresses the multiple levels of pro-environmental behaviors and their complex connections with values (van Riper et al., 2019). Among other types of actions, social environmentalism is connected to behaviors such as participation in discussions about the environment, volunteering for environmental causes, and working with others on addressing environmental problems. Social environmentalism actions positively correlate with biospheric values but also with egoistic values (van Riper et al., 2019).

\section{Students as agents of change}

Higher education students could be particularly interesting as initiators of proenvironmental social influence actions based on their possible role as environmental change agents. Although there are significant differences between higher education students throughout the world, or even in Europe (Brooks, 2018), commonalities can be found in their experiences and concerns for the environment. 
Firstly, as the likelihood of individuals performing pro-environmental behavior seems to be highest below 30 years and declines with age (Blankenberg \& Alhusen, 2018), students might be more inclined to urge others to act more environmentally friendly than people of other age groups. University students are also increasingly concerned about the environment compared to previous years (Cortes, Dias, Fernandes, \& Pamplona, 2016), which could be related to their educational levels, as an increased education is connected to greater awareness of environmental issues and concern with welfare, thus leading to a higher likelihood of acting pro-environmentally (Blankenberg \& Alhusen, 2018).

Furthermore, similarly to children who have been characterized as agents of change based on a possible bi-directional influence between children and their parents (Damerell, Howe, \& Milner-Gulland, 2013; Vaughan, Gack, Solorazano, \& Ray, 2003), students could act as agents of change within the origin family. Recent trends point to a tendency of higher education students moving back to parental homes after graduation (Heath, Davies, Edwards, \& Scicluna, 2018; Maguire, Ball, \& MacRae, 2003), which could lead to renewed close contact with origin families. Later, they might also influence their own significant others and children.

Additionally, most students in the Netherlands choose universities in different cities than their origin families (van Hulle et al., 2015). About 52\% of students studying in the Netherlands move when they enroll in higher educational institutions (van Hulle et al., 2015), and this might be their first time living away from their families. Although some universities provide student halls or other means of housing, others - especially in the Netherlands - tend to have no or low availability of student accommodation (Nijënstein, Haans, Kemperman, \& Borgers, 2015). Most students in university education, therefore, start their independent housing career in shared housing situations (Mulder \& Hooimeijer, 2002), usually either 
renting one room of a student house or sharing an apartment with fellow students (Nijënstein et al., 2015).

\section{The role of households, shared housing, and student households}

Although most policy measures related to energy efficiency affect households as units without much regard to their structure, the make-up of the household and the differing beliefs and behaviors of their members are determinants of the actual energy consumed or conserved by the household. Household members may even engage in conflicting actions depending on their preferences and everyday activities, thus it could be important to be aware of the behaviors and values of individuals living within the same household (Seebauer, Fleiß, \& Schweighart, 2017). As of now, related studies seem to have mainly focused on differences and similarities between members of families and couples living in one household (Longhi, 2013; Seebauer et al., 2017; Thøgersen \& Grønhøj, 2010).

Yet, researchers seem to ignore prevalent, but less conventional, household structures such as shared housing situations. Shared housing or flatting situations involve at least two people living in a house or apartment and sharing some parts of the living areas (e.g., bathrooms, kitchens or living rooms) but exclusively utilizing other areas (e.g., their own rooms; Clark, Tuffin, Bowker, \& Frewin, 2018). Individuals living in such situations are generally unrelated, single, childless, employed or studying, and geographically flexible (Clark et al., 2018).

For several reasons, such as growing population size and rising housing costs, house sharing seems to be more common than generally assumed and is expected to increase, representing the largest relative change in comparison with other household types (Heath et al., 2018). House sharing is especially characteristic for students in the UK (Heath et al., 2018) and the Netherlands (van Hulle et al., 2015; van Hulle, Hooft, Marchal, Zwaneveld, \& Vijncke, 2017). However, even though shared housing is a growing phenomenon in Europe, 
literature on the social dynamics and interpersonal relationships involved in such situations seems to be scarce (Clark et al., 2018; Clark, Tuffin, Frewin, \& Bowker, 2017)

Even though shared households are different from familial households in their structures, in many respects these differences are minimal. In both types of households, chores and economic costs have to be negotiated, relationships can become quite complex and intimate, individuals live in close proximity to each other, and sharing relationships are often characterized by a sense of connectedness (Heath et al., 2018). Thus, although relatively little is known about psychological effects of shared living situations (Ahrentzen, 2003), findings about familial households could hold in flatting situations as well. As social influence could be a key facilitator of energy-based-household actions such as washing in cold water or using the heater less (Allison, 2015), shared household members could be also subject to the influence of other members, which in turn could lead to a change in energy conservation behavior.

\section{Current research}

Most researchers have examined how values are related to private actions. Although little is known about the extent to which values are related to actions to motivate others to engage in pro-environmental actions, some findings could be useful to address this gap. Firstly, although Sloot and colleagues (2018) found no relationship between other-directed behaviors and biospheric values, this relationship could be present for household-level social influence actions of a non-political nature. They found that some of the other-directed behaviors had a positive relationship with egoistic values, which could be reflect a need for influence over others. This argument might be transferable to influences within households, as urging peers to act in a certain manner could be motivated by a need for influence (Bourgeois et al., 2009). 
Secondly, social environmentalism actions seem to be best related to household-level social influence actions as they are targeted towards influencing peers to act more environmentally friendly. Although findings seem to be scarce related to the connection between value types and social environmentalism, biospheric and egoistic values have been found to be related to such actions (van Riper et al., 2019), suggesting that, contrary to previous findings and expectations, biospheric and egoistic values could be simultaneously related to the likelihood that people urge others to act pro-environmentally.

Based on these findings, we propose that stronger biospheric values may particularly increase the likelihood that one tries to urge others to act pro-environmentally among those who also have stronger egoistic values. Doing so would imply that they act in line with their biospheric values (engage in behavior that protects the environment) as well as in line with their egoistic values (exercise influence over others).

Accordingly, we aimed to examine the extent to which biospheric and egoistic values are related to people's tendency urge others to act pro-environmentally. We hypothesized that biospheric values would be positively related to the likelihood that people engage in social influence behaviors, urging their housemates to act pro-environmentally (H1).We secondly hypothesized that egoistic values would be positively related to the likelihood that people engage in social influence behaviors, urging their housemates to act pro-environmentally (H2). Lastly, we hypothesized that there would be a significant interaction between biospheric and egoistic values such that biospheric values would be more strongly associated with the likelihood that people engage in social influence behaviors, urging their housemates to act pro-environmentally as egoistic values increase, as illustrated by Figure $1(\mathrm{H} 3)$. 


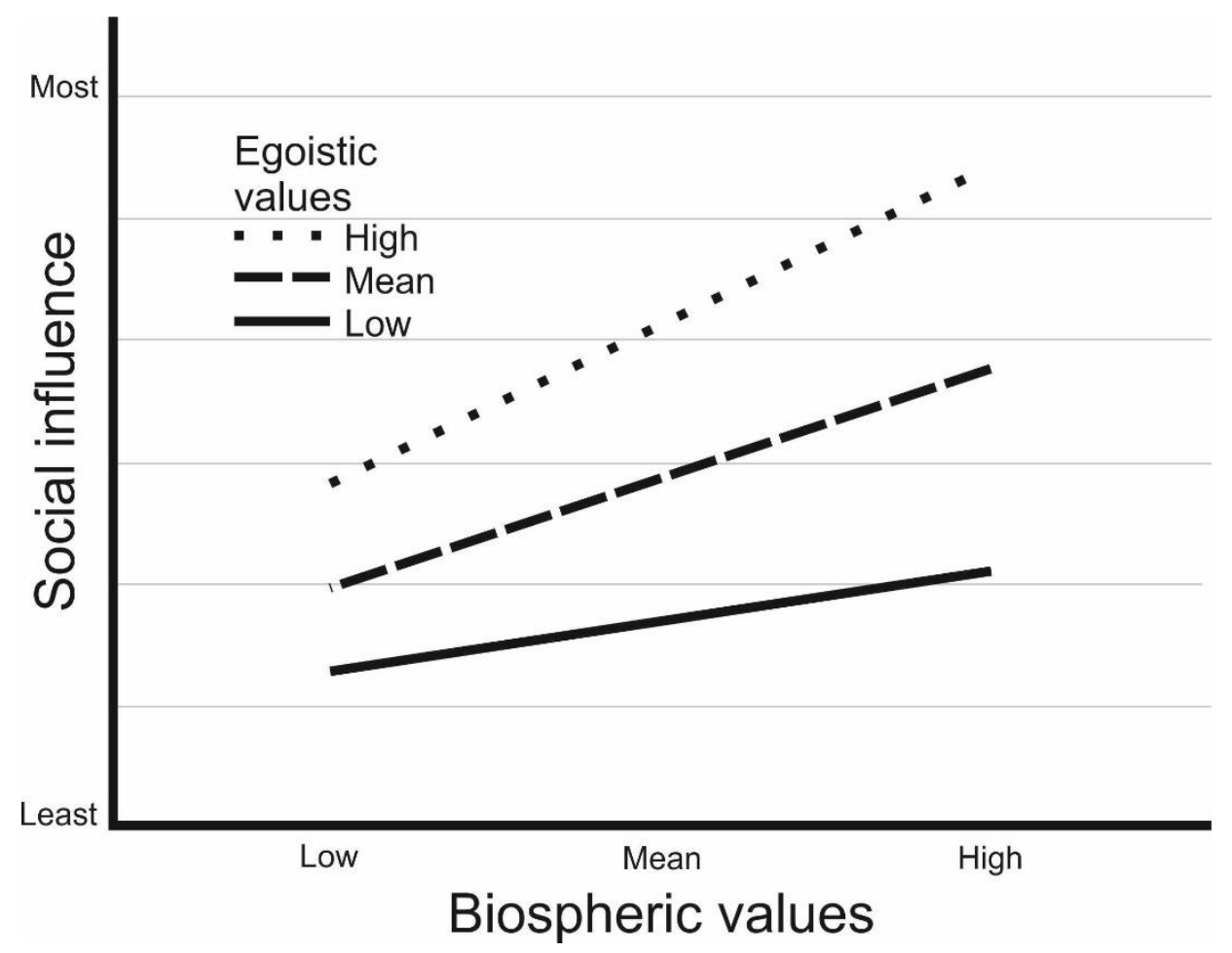

Figure 1. Interaction proposed by the second hypothesis

To investigate these research questions, we conducted a questionnaire study among students sharing a household who regularly interact with each other and who need to coordinate some behaviors with the other student inhabitants (e.g., to decide on the room temperature in shared rooms). Participants answered questions related to their values and about the frequency of behaviors intended to urge household members to conserve more energy.

\section{Methods}

\section{Recruitment and participation}

In line with an a priori power analysis conducted in $\mathrm{G}^{*}$ Power, we aimed to recruit a minimum of 156 students (with an effect size of $\mathrm{f}^{2}=0.04, \alpha=0.05$, power of 0.80 and three predictors for one-tailed power) students who study in the Netherlands, at the University of Groningen, and who live together with at least one other student. We recruited students through SONA, the research participation portal of the University of Groningen and 
participants were psychology students mainly in their first-year. Participants received 0.4 course credits in exchange for participation and were asked to fill in an online questionnaire.

\section{Exclusion criteria}

Before we collected the data, we decided on several preliminary exclusion criteria. We excluded from the initial sample: (1) responses without SONA identification numbers, (2) duplicated responses based on the SONA identification numbers, (3) responses given by participants who did not agree to using their data, and (4) responses given by participants who did not meet the participation criteria (i.e., were not students, living in Groningen, living together with at least one other student). The initial sample after applying these criteria was 220 students. Responses with all data missing $(\mathrm{N}=1)$ and responses from participants who had no contact with household members $(\mathrm{N}=26)$ were considered invalid. The actual sample after the removal of invalid responses was 193 (63\% female), with a mean age of 21 years, 95\% CI [20.73, 21.79]. The percentage of the total sample retained was $87.73 \%$.

\section{Procedure and measures}

The online questionnaire firstly asked participants to consent to participate in the study and to the use of their data. Participants then completed six blocks of questions and lastly arrived at the debriefing message, see in the online appendices. All participants completed the questionnaire in the same order, as given below.

Values. Participants completed the short version of Schwartz's (1992) value scale developed by Steg, Perlaviciute, van der Werff, and Lurvink (2014). The16 items (e.g., "That I have nice meals") all related to the initial question 'What do you find important?' Items were rated on a 7-point Likert scale from 1, 'not important' to 7, 'very important', with an additional option of 'I don't know'. Higher scores indicated stronger values. Items corresponding to each of the four values (altruistic, biospheric, egoistic, hedonic), were grouped together, and a mean score for each value scale was calculated. The altruistic values 
subscale consisted of 4 items $(\alpha=.70)$, the biospheric values subscale consisted of 4 items ( $\alpha$ $=.79)$, the egoistic values subscale consisted of 5 items $(\alpha=.77)$, and the hedonic values subscale consisted of 3 items $(\alpha=.80)$. All items are given in the online appendices. Reliability of items within the scale are reported in the supplementary material.

Social influence behavior. Next, participants completed our Environmental Social Influence Behavior questionnaire. Here we asked participants to rate the frequency of their social influence behavior (i.e., actions intended to urge others to act pro-environmentally) by rating items related to the following question: "How often do you influence household members to perform the following actions?" We adapted eight items based on the energy conservation behavior measures listed by Blankenberg and Alhusen (2018) to be more appropriate for students (e.g., "To turn off the lights when leaving the room."; "To shower less than 5 minutes"). Participants rated the items on a 7-point Likert-scale from 1, 'never', to 7, 'always', with additional options of 'I don't know' and 'does not apply/my household members already do this'. Higher scores indicated that they more often engaged in the behavior. For each participant the means of their influence behavior scores was calculated. The social influence behaviors scale had a high reliability for this sample, with Cronbach's $\alpha$ $=.84$. All items are given in the online appendices. Reliability of items within the scale are reported in the supplementary material.

Demographics. Participants then answered demographic questions (e.g., year of birth, gender, nationality, level of education, and major).

Household information. Participants reported their household situation. We used two items to measure contact with their household members: "How long have you been living in this household? Please provide your answer in the number of months."; “On average, how much time do you spend together with your household members?" For the latter, they indicated their perception of the amount of time spent together on a 5-point Likert scale 
ranging from 1, 'a great deal', to 5, 'none at all'. We also asked: 'How many household members are you currently living with (not counting yourself)?"

Verification questions. As an exclusion criterion, and to verify that participants were students, living in Groningen, and sharing a household with other students, we asked three yes-no verification questions: “Are you a student?”; "Do you live in Groningen?”; “Do you live in a house with other students?" Participants $(n=34)$ who answered 'no' to any of the three items were excluded.

\section{Data Analysis}

We analyzed all data using IBM SPSS Statistics 26.0® for Windows. Means and 95\% confidence intervals for the variables studied are displayed in Appendix B. Prior to analysis, we checked the data for missing values and outliers. We winsorized outliers as described by Field (2018). To test the hypotheses and examine the strength of the relationships between biospheric and egoistic values and their interaction on social influence behavior, a moderated multiple regression analysis was conducted using PROCESS macro version 3.3. To help with the interpretation of interaction effects, we calculated slopes of lines fitted to mean social influence scores predicted from biospheric value levels at low (1SD below the mean), medium (at the mean), and high (1SD below the mean) levels of egoistic values.

Missing data. The overall percentage of missing data within predictor and outcome variables was $4.78 \%$, with $89(46.11 \%)$ cases incomplete. Although most variables had a relatively small percentage of data missing, some items had up to $22.3 \%$ of data missing. A Missing Values Analysis indicated that Little's Missing Completely at Random (MCAR) Test (Little, 1988) was not significant, $\chi^{2}(14, n=89)=1387.99, p=.354$, suggesting that the data were MCAR. As such, multiple imputation was used (Manly \& Wells, 2015); data were imputed five times, replacing missing values with estimated values.

Assumptions. Our data met all assumptions of multiple linear regression. 


\section{Results}

A moderated multiple regression analysis was conducted, with the model statistics given in Table 1. Table 1 shows that biospheric and egoistic values both significantly and positively predicted social influence behavior, and the interaction of the two predictor variables was also significant.

Table 1

Regression Analysis Examining the Interaction between Biospheric and Egoistic Values on Social Influence Behaviors

\begin{tabular}{lccccccccc}
\hline & & & & & & & & \multicolumn{2}{c}{$95 \%$ Confidence Interval } \\
\cline { 6 - 9 } & & $S D$ & $b$ & $S E B$ & $t$ & $p$ & $L L$ & $U L$ \\
\hline 1. Biospheric values & 5.81 & 0.91 & .35 & .11 & 3.27 & .001 & .14 & .56 \\
2. Egoistic values & 3.95 & 1.12 & .21 & .09 & 2.42 & .017 & .04 & .38 \\
Interaction $1 \times 2$ & & & -.21 & .09 & -2.38 & .018 & -.39 & -.04 \\
\hline
\end{tabular}

Notes: ${ }^{\mathrm{a}} \mathrm{n}=193 . \mathrm{LL}=$ lower limit; $\mathrm{UL}=$ upper limit. Final model: $\mathrm{F}(3,189)=6.12, p<0.001 ;$ total $\mathrm{R}^{2}=.09 . b$ $=$ unstandardized regression coefficient; SE B = standardized error.

Figure 2 illustrates the moderation effect of egoistic values between biospheric values and social influence behaviors, where biospheric values became a stronger predictor of social influence behaviors as egoistic values decreased. For example, when egoistic values were low, there was a significant positive relationship between biospheric values and social influence behaviors, $b=.59,95 \%$ CI $[.28, .89], t=3.79, p<.001$. At the mean egoistic value, there was also a significant positive relationship between biospheric values and social influence behaviors, $b=.35,95 \%$ CI $[.14, .56], t=3.27, p=.001$. However, when egoistic values were high, the relationship between biospheric values and social influence behaviors became non-significant, $b=.11,95 \%$ CI $[-.16, .38], t=.80, p=.424$. Covariates (i.e., number of months spent in the same household, amount of contact between household members, and number of household members) did not have any significant effect on the outcome. Therefore, the analyses showed that the relationship between biospheric values and influence behavior weakened as scores on the egoistic scale increased. 


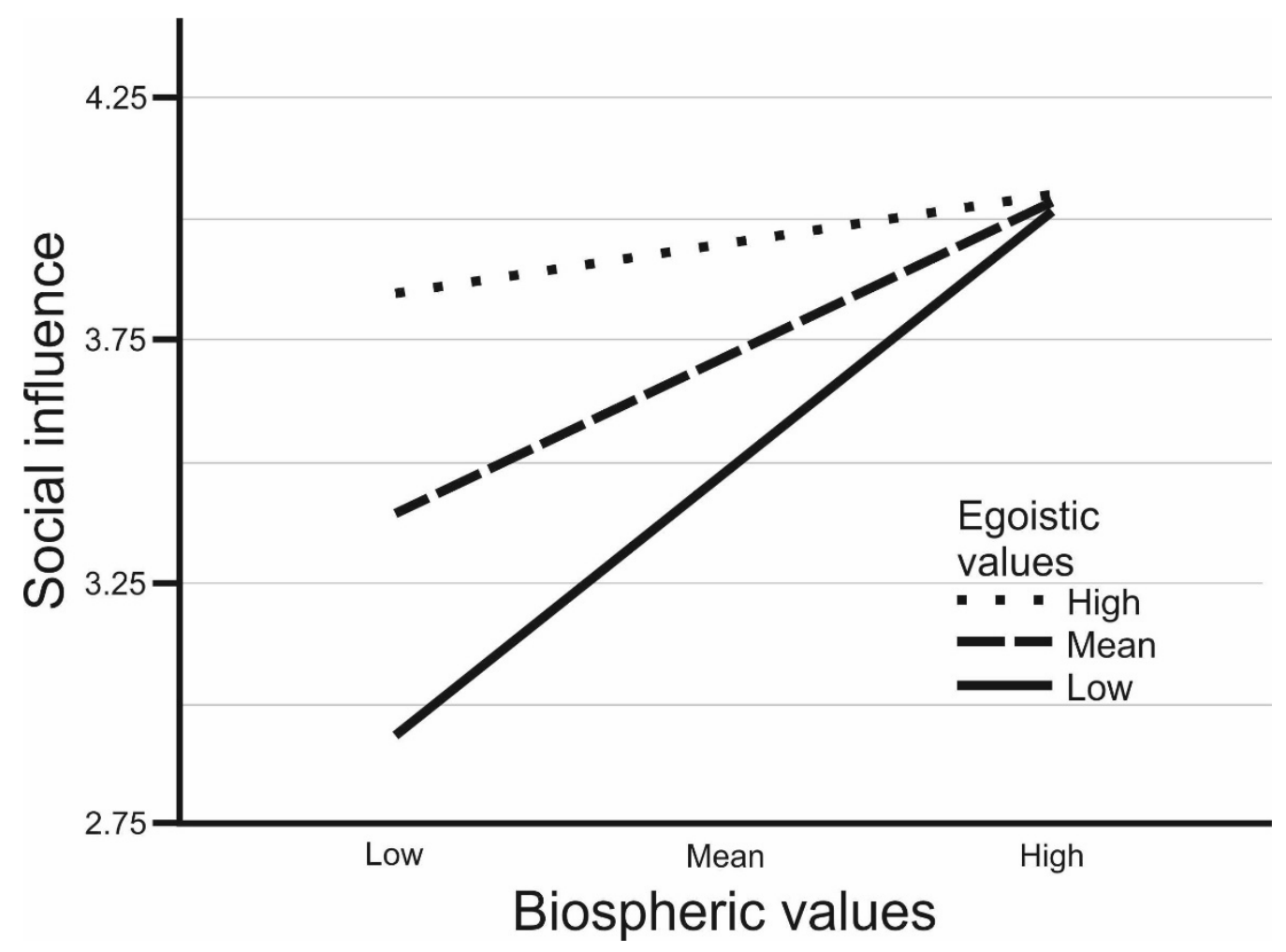

Figure 2. Moderation effect of egoistic values on the relationship between biospheric values and social influence behavior.

The egoistic scale is comprised of a number of items, some of which appear to be more relevant to social influence than others. Therefore, we explored the role of specific egoistic values. For this, a moderated multiple regression analysis was conducted with each of the five items within the egoistic values scale after checking for outliers and assumptions. From the five items, only social power (i.e., having control over others) and authority (i.e., being in charge and telling others what to do) were found to be predictors of social influence behavior and have a significant interaction with biospheric values, as described in Table 2 . The interaction effect for the two subscales and biospheric values on social influence behavior was similar to that shown in Figure 2.

Table 2

Regression Analysis Examining the Interaction between Biospheric Values and Sub-items of Egoistic Values on Social Influence Behaviors

\begin{tabular}{lcccccc}
\hline Variables $^{\mathrm{a}}$ & $b$ & SE B & $t$ & $p$ & & \multicolumn{2}{c}{$95 \%$ Confidence Interval } \\
\cline { 5 - 6 } & & & & & $L L$ & $U L$ \\
\hline 1. Biospheric values & .37 & .11 & 3.44 & .001 & .16 & .58
\end{tabular}




\begin{tabular}{lcccccc} 
2. Social power & .12 & .06 & 2.20 & .029 & .01 & .23 \\
Interaction $1 \times 2$ & -.15 & .06 & -2.55 & .012 & -.26 & -.03 \\
\hline 1. Biospheric values & .41 & .11 & 3.78 & .001 & .19 & .62 \\
2. Authority & .15 & .06 & 2.67 & .008 & .04 & .27 \\
Interaction $1 \times 2$ & -.18 & .06 & -3.05 & .003 & -.30 & -.06 \\
\hline
\end{tabular}

Notes: ${ }^{\mathrm{a}} \mathrm{n}=193 . \mathrm{LL}=$ lower limit; $\mathrm{UL}=$ upper limit. Final model with social power: $F(3,189)=6.03, p<$ 0.001 ; total $\mathrm{R}^{2}=.09$. Final model with authority: $F(3,189)=7.50, p<0.001$; total $\mathrm{R}^{2}=.11 . b=$ unstandardized regression coefficient; $\mathrm{SE} \mathrm{B}=$ standardized error.

\section{Discussion}

Given the importance of reducing environmental issues, it is important to understand why some individuals might be more willing to urge others to make a difference by acting more environmentally friendly. In this paper, we examined whether biospheric and egoistic values influence pro-environmental social influence behavior, with a special focus on the interaction of these two value types. Overall, we found that both biospheric values and egoistic values promote social influence behavior, and there is a difference in the extent to which these actions are influenced by biospheric values based on the strength of egoistic values.

Accordingly, and as expected based on the literature (Sloot et al., 2018; van Riper et al., 2019), the first hypothesis was supported, that is, biospheric values positively predicted the likelihood that people urge others to act pro-environmentally. The second hypothesis was also supported, as egoistic values also positively predicted pro-environmental social influence behavior. Notably, biospheric values were found to be a more important predictor of social influence behavior than egoistic values. The third hypothesis was not supported. Although the effect of biospheric values was influenced by the strength of egoistic values, this effect was in the opposite direction than predicted. That is, biospheric values more strongly predicted influence behavior when egoistic values were low, and not when they were high. 
When egoistic values were high, there was no relationship between biospheric values and influencing behavior, but as egoistic values decreased, the relationship between biospheric values and influencing behavior became stronger. So, people with high egoistic values reported influencing their housemates to behave pro-environmentally, even when they had low biospheric values. Similarly, people who had had biospheric values reported influencing their housemates to act pro-environmentally even when they had low egoistic values. However, when egoistic values were low, biospheric values became important, with higher biospheric values leading to more urging.

The reason for these somewhat unexpected results is unclear. We posited that those with stronger biospheric and stronger egoistic values would be the most likely to engage in pro-environmental social influence behavior. Results opposing these expectations could indicate that those with stronger biospheric values were more likely to communicate some of their concerns related to climate change regardless of their concerns for self-enhancement. People endorsing biospheric values are reportedly more likely to be concerned about both the consequences, and seriousness of climate change (Corner, Markowitz, \& Pidgeon, 2014), so, even when less interested in telling others what to do, these individuals might have felt the need to express environmental concerns by urging others to better their actions. However, as this explanation is speculative, further research is needed.

Moreover, when all five items within the egoistic value scale were considered separately, only two of these items, namely social power and authority were found to have an influence on the effect of biospheric values and social influence behaviors. This result partly supports our theoretical reasoning, as it seems to be in line with some of the goals served by social influence as proposed by Bourgeois and colleagues (2009): They proposed that wanting to influence others could be motivated by a need for having control. 
Correspondingly, both the social power and the authority item reflect needs for having control over others and telling others what to do.

Yet, contrary to previous assumptions, the influence item that reflects concerns for having an influence over other people or events (i.e., "I find it important that I have influence on other people and on what happens") did not result in a significant effect on the interaction. One explanation for why the influence item had no impact on social influence behavior could be because participants interpreted the concepts underlying this item differently than we did. It is possible for example, that participants understood the type of influence described by the item as one referring to large-scale actions (e.g., influencing political decision makers or protests) instead of interpersonal behaviors. Notably, difference in the understanding of questions is one of the prevailing reasons why the validity of self-report questionnaires is often questioned (Lange \& Dewitte, 2019).

Furthermore, our findings seem to be in line with the way Sloot and colleagues (2018) interpreted their results: They revealed large-scale social influence actions such as proenvironmental lobbying to be connected to egoistic value items like being ambitious or influential and reasoned that this connection could be based on one's ambitions and need to influence decision makers to support their goals. Based on this, it seems reasonable to presume that while the items measuring social power and authority suggest having an influence on those proximate to the individual, other items might be better associated with a different type of influence related to political actions. Further research could investigate this assumption by addressing both types of social influence behaviors and all five items of the egoistic value scale.

Finally, neither the amount of contact with members of the household, the number of household members, nor the amount of time household members have been living together affected the frequency of their social influence behaviors, implying that the dynamics of 
social influence within student households was better predicted by psychological constructs than mere contextual factors.

\section{Theoretical and practical implications}

These results have notable theoretical implications. Firstly, although some authors argue for the importance of egoistic values for pro-environmental actions (Dominicis et al., 2017), and argue for further examination of egoistic values by decomposing the egoistic value scale into sub-dimensions to assess their influence on pro-environmental actions (Sloot et al., 2018), corresponding literature seems to be scarce. Our results support these suggestions, signifying a need for development of new lines of research within environmental psychology.

In turn, as some extant studies on social influence behaviors reflecting concerns for the environment (e.g., studies on social environmentalism or other-directed actions) are scarce and fragmented, the current approach might draw attention to the need to summarize and deliberate on pro-environmental social influence behavior. Correspondingly, related definitions could be broadened to include several types of behaviors. The Environmental Social Influence Behavior questionnaire constructed for the current research produced high internal consistency reliability and, as such, offers promise as a tool to further research on social influence as it relates to pro-environmental behavior. However, as this was the first study conducted to use the scale, empirical and theoretical validity should be further assessed before future implementation.

As values are relatively stable personality dimensions (Corner et al., 2014), our results should not be applied to changing the values of individuals in the hope that they will engage in more pro-environmental social influence behaviors. However, our results might be useful in promoting pro-environmental behavior by appealing to pre-existing values held by individuals. For example, value-congruent messages are found to be effective for 
environmental campaigns, meaning that if the content of an environmental campaign is tailored to the values of its target audience, it is likely to be well received (Corner et al., 2014). Noting that egoistic values - and certain types of egoistic values in particular - can promote pro-environmental social influence could be an important step towards reaching an important new target group: People concerned with social power and with lower levels of biospheric values could be affected by such value-tailored messages. That is, our findings have shown that people with egoistic values are more likely to try to influence the behavior of their housemates than those with low egoistic values. Therefore, this population could be exploited as environmental advocates if they could be encouraged to promote more proenvironmental behaviors. One way to do this might be appeal to their need to influence others - if people high in egoistic values feel that they will gain in status or influence by encouraging pro-environmental behaviors, they may perform such influencing behaviors regardless of their biospheric values.

However, Thøgersen and Crompton (2009) argue that framing messages in congruence with the target audiences values is only beneficial in the long-term when the message reflects pro-environmental values. They reason that using other imperatives might inhibit the adoption of other environmentally friendly behaviors, contrary to following instructions built around environmental values. This reasoning seems to be true in case of traditionally researched environmental actions and egoistic values connected to money. However, as social influence behaviors are determined by both biospheric and (some) egoistic values reflecting concerns for social power and authority, this type of proenvironmental social influence behavior might serve as a new opportunity for reaching out to individuals previously neglected. In this case this would mean that individuals with low biospheric values could be influenced to urge others by appealing to their egoistic values. Or, by targeting both values, a new identity could arise from these types of messages, making 
egoistic individuals think of themselves as opinion leaders or advocates for environmentalism. As most previous research-based interventions were focused on biospheric and altruistic values, incorporating egoistic concerns could be a novel approach to promoting pro-environmental behaviors based on values.

\section{Limitations and Directions for Further Research}

For the correct interpretation of this paper, several study limitations should be noted. Although using a student sample was intentional in this case, participants were limited to first-year psychology students studying in Groningen. This makes the findings less generalizable, as the results might be dissimilar for student populations with different majors, or age and gender distributions. Students majoring in psychology have been reported to differ significantly from other students regarding their environmental attitudes (Arnocky \& Stroink, 2011; Isildar \& Yildirim, 2008; Kukkonen, Kärkkäinen, \& Keinonen, 2018; Lang, 2011).

In addition, as concerns with saving resources (e.g., saving energy) have been found to differ for students following different majors (Kukkonen et al., 2018), and in our study participants were asked about household energy conservation, there could also be differences related to this specific type of environmental action. Furthermore, age and gender are known to predict pro-environmental behaviors and environmental attitudes (Blankenberg \& Alhusen, 2018; Wachholz, Artz, \& Chene, 2014). These sample characteristics limits generalizations of current findings even within the student population. To address this limitation, this study could be repeated in future research with more representative samples of students, or a wider population.

Another limitation is the questionnaire used in this study. Firstly, all results are based on self-report measures, that is, participants provided information on their values and behaviors via an online questionnaire. While self-report measures are often used when measuring values and behaviors related to environmentalism, their validity has often been 
questioned (Lange \& Dewitte, 2019). Concerns for validity include arguments about how individuals are not impartial observers when it comes to their own actions, they might interpret concepts within questions differently than others or from the constructors of the questions, and questionnaires may prove cognitively demanding when asking for reports on retrospective behaviors (Lange \& Dewitte, 2019). Future research could use other methods that might lessen misreporting, such as diary studies, or observational methods.

In addition, the behavioral scale was self-constructed based on the energy conservation behavior measures described by Blankenberg and Alhusen (2018). Notably, items within the influence behavior scale had higher amounts of data missing, which could mean that although the scale was found to be reliable, some items might not relate well to the experiences of students in shared household situations. As our study was the first to use such a questionnaire, reliability and validity should be further tested within different households and optimized based on both quantitative and qualitative data gained from different samples.

Researching other types of pro-environmental social influence behavior could also be an interesting direction to follow as it may lead to insights on the underlying values of social influence. As probably most well-known environmentally friendly actions could be studied in this regard, items measuring actions such as recycling (e.g., asking other household members to recycle bottles), or consuming less meat (e.g., urging other people to eat less meat) could be developed based on our household energy conservation items developed for this study. Finding connections between likely actions conducted by specific target groups and the types of actions studied is always important, otherwise participants are likely to be unable to adequately report their behaviors.

Possible moderating or mediating variables could also be investigated. We only examined the possible influence of contact with household members, but relatively less is known about non-familial household dynamics. It would be valuable to see how constructs 
related to group dynamics such as social norms, group identification or group entitativity might promote or inhibit the occurrence of different types of social influence actions.

Qualitative research could also uncover potential reasons for social influence that might be unexpected.

It should be noted that the household conservation behaviors this study measured constitute a special type of pro-environmental behavior, as they might be motivated by hopes of saving money instead of concerns for the environment. Although this reasoning seems unlikely, as the wealth item of the egoistic value scale did not impact social influence behavior, a more explicit control measure (e.g., asking for an explanation of why one is likely to act accordingly) could help in completely excluding this alternative explanation. In addition, our measures were exclusively related to pro-environmental behaviors, yet it is likely that people high in egoistic values will try to influence their housemates to engage in a whole range of behaviors - they may be simultaneously encouraging them to engage in unsustainable behavior. Future research should include a wider range of behaviors to test for this.

Finally, looking at the broader literature, as household energy use cannot be determined based on a single person's actions, it should be rather examined based on the actions of other household members (Seebauer et al., 2017). Also, as we don't know whether influence behaviors have the intended result - that is, whether the person intended to be influenced will act in accordance with the message of the influencer - determinants of success of this type of action could also be examined. Following a new trend in related research, network analysis could be a valuable tool to measure how values or actions of household members could become similar over time.

\section{Conclusions}


In sum, our results showed that both biospheric and egoistic values can promote proenvironmental social influence behaviors. Biospheric values were more impactful on such actions, but egoistic values moderated this relationship. As one of the first studies developed to examine connections between pro-environmental social influence behaviors and egoistic values, the results of this paper have important theoretical implications and suggest that research in environmental psychology should further explore relationships between all value types and environmental behavior. 


\section{References}

Abrahamse, W., \& Steg, L. (2009). How do socio-demographic and psychological factors relate to households' direct and indirect energy use and savings? Journal of Economic Psychology, 30, 711-720. https://doi.org/10.1016/j.joep.2009.05.006

Ahrentzen, S. (2003). Double indemnity or double delight? The health consequences of shared housing and "Doubling Up.” Journal of Social Issues, 59, 547-568. https://doi.org/10.1111/1540-4560.00077

Allison, L. (2015). The impact of social interaction, local leadership and other influences on household energy based practices: Confirmation Document. (September), 0-132.

Arnocky, S., \& Stroink, M. L. (2011). Variation in environmentalism among university students: Majoring in outdoor recreation, parks, and tourism predicts environmental concerns and behaviors. Journal of Environmental Education, 42, 137-151. https://doi.org/10.1080/00958964.2010.516776

Benders, R. M. J., Kok, R., Moll, H. C., Wiersma, G., \& Noorman, K. J. (2006). New approaches for household energy conservation-In search of personal household energy budgets and energy reduction options. Energy Policy, 34, 3612-3622. https://doi.org/10.1016/j.enpol.2005.08.005

Blankenberg, A.-K., \& Alhusen, H. (2018). On the Determinants of Pro-Environmental Behavior - A Guide for Further Investigations. SSRN Electronic Journal, 350. https://doi.org/10.2139/ssrn.3186089

Bouman, T., Steg, L., \& Kiers, H. A. L. (2018). Measuring values in environmental research: A test of an environmental Portrait Value Questionnaire. Frontiers in Psychology, 9. https://doi.org/10.3389/fpsyg.2018.00564

Bourgeois, M. J., Sommer, K. L., \& Bruno, S. (2009). What do we get out of influencing others? Social Influence, 4, 96-121. https://doi.org/10.1080/15534510802465360 
Brooks, R. (2018). Understanding the higher education student in Europe: a comparative analysis. Compare, 48, 500-517. https://doi.org/10.1080/03057925.2017.1318047

Clark, V., Tuffin, K., Bowker, N., \& Frewin, K. (2018). A fine balance: A review of shared housing among young adults. Social and Personality Psychology Compass, e12415, 112. https://doi.org/10.1111/spc3.12415

Clark, V., Tuffin, K., Frewin, K., \& Bowker, N. (2017). Shared housing among young adults: avoiding complications in domestic relationships. Journal of Youth Studies, 20, 11911207. https://doi.org/10.1080/13676261.2017.1316834

Corner, A., Markowitz, E., \& Pidgeon, N. (2014). Public engagement with climate change: The role of human values. Wiley Interdisciplinary Reviews: Climate Change, 5, 411422. https://doi.org/10.1002/wcc.269

Cortes, P. L., Dias, A. G., Fernandes, M. E. da S. T., \& Pamplona, J. M. V. (2016). Environmental behaviour: A comparative study between brazilian and portuguese students. Ambiente \& Sociedade, 19(3), 113-134. https://doi.org/10.1590/18094422asoc139099v1932016

Damerell, P., Howe, C., \& Milner-Gulland, E. J. (2013). Child-orientated environmental education influences adult knowledge and household behaviour. Environmental Research Letters, 8. https://doi.org/10.1088/1748-9326/8/1/015016

de Groot, J. I. M., \& Steg, L. (2008). Value orientations to explain beliefs related to environmental significant behavior: How to measure egoistic, altruistic, and biospheric value orientations. Environment and Behavior, 40, 330-354. https://doi.org/10.1177/0013916506297831

Dominicis, S. De, Schultz, P. W., \& Bonaiuto, M. (2017). Protecting the Environment for Self-interested Reasons : Altruism Is Not the Only Pathway to Sustainability. 8(June), 113. https://doi.org/10.3389/fpsyg.2017.01065 
European Environment Agency. (2012). End-user GHG emissions from energy. In EEA Technical report 18/2012. https://doi.org/10.2800/69040

European Environment Agency. (2018). Final energy consumption by sector and fuel.

Field, A. (2017). Discovering Statistics Using IBM SPSS Statistics. In SAGE Publications Ltd.

Forgas, J., \& Williams, K. (2001). Social influence: Direct and indirect processes. The Sydney Symposium of Social Psychology Series, v. 3. Philadelphia: Psychology Press.

Goldsmith, E. B., \& Goldsmith, R. E. (2011). Social influence and sustainability in households. International Journal of Consumer Studies, 35(2), 117-121. https://doi.org/10.1111/j.1470-6431.2010.00965.x

Heath, S., Davies, K., Edwards, G., \& Scicluna, R. M. (2018). Shared housing, shared lives: Everyday experiences across the lifecourse. New York, NY: Routledge.

Hogg, M. A., \& Cooper, J. (2007). The SAGE Handbook of Social Psychology: Concise Student Edition. SAGE Publications Ltd.

IPCC. (2018). Summary for Policymakers of IPCC Special Report on Global Warming of $1.5^{\circ} \mathrm{C}$. In Special Report on Global Warming of 1.5C (SR15).

Isildar, G. Y., \& Yildirim, F. (2008). The Effectiveness of Environmental Education on Environmentally- Sensitive Behaviors. Egitim ve Bilim, 33(148), 13-27.

Kukkonen, J., Kärkkäinen, S., \& Keinonen, T. (2018). Examining the relationships between factors influencing environmental behaviour among university students. Sustainability (Switzerland), 10, 4294. https://doi.org/10.3390/su10114294

Lang, K. B. (2011). The relationship between academic major and environmentalism among college students: Is it mediated by the effects of gender, political ideology and financial security? Journal of Environmental Education, 42, 203-215. https://doi.org/10.1080/00958964.2010.547230 
Lange, F., \& Dewitte, S. (2019). Measuring pro-environmental behavior: Review and recommendations. Journal of Environmental Psychology, 63, 92-100. https://doi.org/10.1016/j.jenvp.2019.04.009

Larson, L. R., Stedman, R. C., Cooper, C. B., \& Decker, D. J. (2015). Understanding the multi-dimensional structure of pro-environmental behavior. Journal of Environmental Psychology, 43, 112-124. https://doi.org/10.1016/j.jenvp.2015.06.004

Lind, H. B., Nordfjærn, T., Jørgensen, S. H., \& Rundmo, T. (2015). The value-belief-norm theory, personal norms and sustainable travel mode choice in urban areas. Journal of Environmental Psychology, 44, 119-125. https://doi.org/10.1016/j.jenvp.2015.06.001

Little, R. J. A. (1988). A test of missing completely at random for multivariate data with missing values. Journal of the American Statistical Association, 83, 1198-1202. https://doi.org/10.1080/01621459.1988.10478722

Longhi, S. (2013). Individual pro-environmental behaviour in the household context. ISER Working Paper Series.

Maguire, M., Ball, S. J., \& MacRae, S. (2003). Post-Adolescence, Dependence and the Refusal of Adulthood. Discourse: Studies in the Cultural Politics of Education, 22, 197211. https://doi.org/10.1080/01596300124693

Manly, C. A., \& Wells, R. S. (2015). Reporting the Use of Multiple Imputation for Missing Data in Higher Education Research. Research in Higher Education, 56, 397-409. https://doi.org/10.1007/s11162-014-9344-9

Mulder, C. H., \& Hooimeijer, P. (2002). Leaving home in the Netherlands: Timing and first housing. Journal of Housing and the Built Environment, 17, 237-268. https://doi.org/10.1023/A:1020264417389

Nakagawa, Y., Mori, K., Nishimura, T., \& Hayashi, K. (2019). Tie to community as a proxy of competency to fill the gap between intended and actual pro-environmental behavior in 
urban settings Tie to community as a proxy of competency to fill the gap between intended and actual pro-environmental behavior in urban se. Social Design Engineering Series, 1 .

Nathan, P. E. (2016). Oxford Handbooks Online: Psychology. 2015-2017.

Nijënstein, S., Haans, A., Kemperman, A. D. A. M., \& Borgers, A. W. J. (2015). Beyond demographics: human value orientation as a predictor of heterogeneity in student housing preferences. Journal of Housing and the Built Environment, 30, 199-217. https://doi.org/10.1007/s10901-014-9402-9

Reber, A. S., \& Reber, E. S. (2001). The Penguin dictionary of psychology. London, New York: Penguin Books.

Schultz, P. W., \& Zelezny, L. C. (1998). Values and proenvironmental behavior a fivecountry survey. Journal of Cross-Cultural Psychology, 29, 540-558. https://doi.org/10.1177/0022022198294003

Schwartz, S. H. (1992). Universals in the content and structure of values: Theoretical advances and empirical tests in 20 countries. Advances in Experimental Social Psychology, 25, 1-65. https://doi.org/10.1016/S0065-2601(08)60281-6

Seebauer, S., Fleiß, J., \& Schweighart, M. (2017). A Household Is Not a Person: Consistency of Pro-Environmental Behavior in Adult Couples and the Accuracy of Proxy-Reports. Environment and Behavior, 49, 603-637. https://doi.org/10.1177/0013916516663796

Sloot, D., Kutlaca, M., Medugorac, V., \& Carman, P. (2018). Recycling alone or protesting together? Values as a basis for pro-environmental social change actions. Frontiers in Psychology, 9(JUL), 1-10. https://doi.org/10.3389/fpsyg.2018.01229

Steg, L., \& de Groot, J. I. M. (Eds.). (2018). Environmental psychology: an introduction. Hoboken, NJ: Wiley-Blackwell.

Steg, L., Dreijerink, L., \& Abrahamse, W. (2005). Factors influencing the acceptability of 
energy policies: A test of VBN theory. Journal of Environmental Psychology, 25, 415425. https://doi.org/10.1016/j.jenvp.2005.08.003

Steg, L., Perlaviciute, G., van der Werff, E., \& Lurvink, J. (2014). The Significance of Hedonic Values for Environmentally Relevant Attitudes, Preferences, and Actions. Environment and Behavior, 46, 163-192. https://doi.org/10.1177/0013916512454730

Stern, P. C. (2000). Toward a Coherent Theory of Environmentally Significant Behavior: EBSCOhost. Journal of Social Issues. https://doi.org/10.1007/BF00640994

Thøgersen, J., \& Crompton, T. (2009). Simple and painless? The limitations of spillover in environmental campaigning. Journal of Consumer Policy, 32, 141-163. https://doi.org/10.1007/s10603-009-9101-1

Thøgersen, J., \& Grønhøj, A. (2010). Electricity saving in households-A social cognitive approach. Energy Policy, 38, 7732-7743. https://doi.org/10.1016/j.enpol.2010.08.025 Truelove, H. B., \& Gillis, A. J. (2018). Perception of pro-environmental behavior. Global Environmental Change, 49, 175-185. https://doi.org/10.1016/j.gloenvcha.2018.02.009 van der Werff, E., \& Steg, L. (2016). The psychology of participation and interest in smart energy systems: Comparing the value-belief-norm theory and the value-identity-personal norm model. Energy Research and Social Science, 22, 107-114. https://doi.org/10.1016/j.erss.2016.08.022

van Hulle, R., Hooft, L., Marchal, B., Vijncke, M., Zwaneveld, J., \& Faessen, W. (2015). Landelijke Monitor Studentenhuisvesting 2018. In ABF Research. Retrieved from http://www.kences.nl/assets/files/2015/Landelijke-Monitor-Studentenhuisvesting-2015def.pdf $\% 5 \mathrm{Cr}$

van Hulle, R., Hooft, L., Marchal, B., Zwaneveld, J., \& Vijncke, M. (2017). Landelijke Monitor Studentenhuisvesting 2017. Retrieved from https://www.kences.nl/assets/files/2017/r2017-0001rh_20171002.pdf 
van Riper, C., Winkler-Schor, S., Foelske, L., Keller, R., Braito, M., Raymond, C., ... Johnson, D. (2019). Integrating multi-level values and pro-environmental behavior in a U.S. protected area. Sustainability Science, 14, 1-14. https://doi.org/10.1007/s11625019-00677-w

Vaughan, C., Gack, J., Solorazano, H., \& Ray, R. (2003). The Effect of environmental education on schoolchildren, their parents, and community members: A study of intergenerational and intercommunity learning. Journal of Environmental Education, 34(3), 12-21. https://doi.org/10.1080/00958960309603489

Wachholz, S., Artz, N., \& Chene, D. (2014). Warming to the idea: University students' knowledge and attitudes about climate change. International Journal of Sustainability in Higher Education, 15, 128-141. https://doi.org/10.1108/IJSHE-03-2012-0025 
Online appendices

Appendix A: Study questionnaire

\section{Explanation + informed consent}

\section{RESEARCH INFORMATION \\ RESEARCH INTO HOUSEHOLD ENERGY BEHAVIORS}

For university students living with at least one other student (students living in student households in Groningen)

\section{Researchers, contact information}

XXX (redacted for peer review)

XXX (redacted for peer review)

Faculty of Behavioral and Social Sciences, University of Groningen

Grote Kruisstraat 2/1

9712 TS Groningen

k.andrea@ student.rug.nl

\section{Introduction, about the research}

You are invited to participate in a study on household energy behaviors. We want to know how households think about energy. Please read the information carefully. Do this before you agree to participate in the study.

The aim of this research is to find out what your opinion is about energy saving. The research consists of one short questionnaire, which you will be able to fill out after reading this information. Filling out this questionnaire takes about 5-10 minutes.

If you agree to participate in this study, we will ask you to first sign an informed consent. Then you can start by completing the short questionnaire. We expect that participation in this study does not entail any risks.

\section{Compensation}

0.4 credits are offered for SONA participants. There is no other type of compensation offered. 


\section{Your privacy}

The data collected during this investigation will be treated confidentially. Your research data are analysed by the researchers at a group level. Research data that are published, for example in scientific journals, cannot be traced back to you. Completely anonymised research data is shared with other researchers for scientific purposes. Your personal information will remain confidential and will not be shared with third parties without your explicit consent. Your other research data will only be shared if they can not be used to identify you. Your privacy is therefore guaranteed.

\section{Participation is voluntary}

Participation in the study is voluntary. It is your choice to participate. You can withdraw from the survey at any time without having to state a reason for doing so. Stopping participation will in no way affect you.

Because your data is processed anonymously, we can not have your already stored research data removed from the database.

\section{Further information}

If you have any questions now, during the survey or afterwards, you can always use the above-displayed contact details to ask the researchers. If you have questions or are concerned about your rights as a research participant, you can contact the Ethics Committee of the Psychology department of the University of Groningen, which can be reached via ecp@ rug.nl.

\section{INFORMED CONSENT}

I have read the research information.

My privacy is guaranteed at all times.

If I decide to stop participating, I do not have to give a reason for this.

I agree to participate in this study. I consent to the use of my data for the purposes stated in the research information.

\section{Values}

What do you find important? 
Not

important
Very I don't

important know
That everyone gets the same opportunities.

That we live together with animals and plants without disrupting their life.

That I have control over other people, that I am in charge.

That I do things that are nice to do.

That I feel that I am part of nature, that I belong to nature.

That there is no war and fighting in the world.

That I have a lot of things or money.

That I am in charge, that I can tell other people what to do.

That everyone gets treated fairly, that people who are less well off than me are taken care of.

That I have nice meals, do nice things.

That the environment is taken care of.

That I have influence on other people and on what happens.

That I do things that make other people happy.

That the environment will not be polluted.

That I do thing that I enjoy to do.

That I work hard, do my best. $\begin{array}{lllllllllllllll}0 & 0 & 0 & 0 & 0 & 0 & 0 & 0\end{array}$

$\begin{array}{llllllll}0 & 0 & 0 & 0 & 0 & 0 & 0 & 0\end{array}$

$\begin{array}{llllllll}0 & 0 & 0 & 0 & 0 & 0 & 0 & 0\end{array}$

0000000000

000000000

000000000

000000000

0000000000

$\begin{array}{llllllll}0 & 0 & 0 & 0 & 0 & 0 & 0 & 0\end{array}$

000000000

$\begin{array}{lllllll}0 & 0 & 0 & 0 & 0 & 0 & 0\end{array}$

0000000000

$\begin{array}{llllllll}0 & 0 & 0 & 0 & 0 & 0 & 0 & 0\end{array}$

$\begin{array}{llllllll}0 & 0 & 0 & 0 & 0 & 0 & 0 & 0\end{array}$

000000000

$\begin{array}{llllllll}0 & 0 & 0 & 0 & 0 & 0 & 0 & 0\end{array}$ 


\section{Energy behaviors}

How often do you influence your household members to perform the following actions?

\begin{tabular}{|c|c|c|c|c|}
\hline & $\begin{array}{l}\text { Not } \\
\text { important }\end{array}$ & $\begin{array}{c}\text { Very } \\
\text { important }\end{array}$ & $\begin{array}{l}\text { I don't } \\
\text { know }\end{array}$ & $\begin{array}{c}\text { Does not } \\
\text { apply/ My } \\
\text { household } \\
\text { members } \\
\text { already do } \\
\text { this }\end{array}$ \\
\hline $\begin{array}{l}\text { To turn off the lights when leaving } \\
\text { the room. }\end{array}$ & 0 & 00000 & & D \\
\hline $\begin{array}{l}\text { To shut off electrical appliances when } \\
\text { not in use (e.g., TV, PC, laptop). }\end{array}$ & 0 & 00000 & & $\mathrm{O}$ \\
\hline $\begin{array}{c}\text { To NOT leave the fridge door open } \\
\text { while they are thinking about what to } \\
\text { eat. }\end{array}$ & 0 & 00 & & ) \\
\hline To shower less than 5 minutes. & 0 & 00000 & & O \\
\hline $\begin{array}{l}\text { To only start the washing machine } \\
\text { when it is full. }\end{array}$ & $\Omega$ & $0 \Omega 000$ & & \\
\hline $\begin{array}{l}\text { To NOT leave the water running } \\
\text { while brushing their teeth. }\end{array}$ & $\Omega$ & 00000 & & ) \\
\hline $\begin{array}{l}\text { To reduce or turn off heating in } \\
\text { unoccupied rooms. }\end{array}$ & 0 & 00000 & $\Omega$ & $\mathrm{O}$ \\
\hline $\begin{array}{l}\text { To NOT leave their mobile phone(s) } \\
\text { on the charger for the night }\end{array}$ & O & 00000 & $\Omega$ & 0 \\
\hline
\end{tabular}

\section{Demographics}

We are interested in some general information.

What is your year of birth?

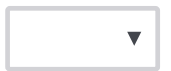

Which gender do you identify most with?
Male
Female
Other / Prefer not to say 
Please specify your nationality

What is your highest completed level of education?

Elementary school

High school

Professional degree (JD, MD, HBO, MBO)

Bachelor's degree

Master's degree

Doctoral degree

What is your major?

\section{Household information}

We are interested in some general information regarding your household.

How long have you been living in this household? Please provide your answer in the number of months.

On average, how much time do you spend together with your household members?
A great deal
O A lot
A moderate amount
O little
None at all

How many household members are you currently living with (not counting yourself)?

Control 
Are you a student?

Yes

No

Do you live in Groningen (during your studies)?

Yes

$\mathrm{O}$ No

Do you live in a house with other students?

Yes

No

\section{Share}

Thank you for participating in this research. Please help our work by sharing this questionnaire with your friends!

Share Tweet

How did you find this study?

I am a SONA participant

Someone shared the link with me

I received a flyer

Please help our work by sharing this questionnaire. You can do so by sharing the following link on your social media accounts or via email:

https://rug.eu.qualtrics.com/jfe/form/SV_9oYq8PWFTbCoLqZ

\section{Experiment debrief information}

Thank you for your time and participation in this study. This research is designed to examine household energy conservation behavior and why individuals might decide to try and influence other household members to conserve energy. For this purpose, we decided to examine the extent to which values influence these types of actions. 
We invited students living in student households. In this questionnaire, you were asked about your values and behaviors aimed at influencing how other household members conserve energy. We wanted to see whether certain values are more strongly related to such actions. The results of this study will serve as the basis of a master's thesis.

Data collected will be safely and anonymously stored and only viewed by the researchers, supervisors and examiners involved in this study. If you have any concerns or further questions, please contact XXX (redacted for peer review) at XXX (redacted for peer review).

\section{Further Reading}

Schwartz, S. H. (1992). Universals in the content and structure of values: Theoretical advances and empirical tests in 20 countries. Advances in Experimental Social Psychology. https://doi.org/10.1016/S0065-2601(08)60281-6

Sloot, D., Kutlaca, M., Medugorac, V., \& Carman, P. (2018). Recycling alone or protesting together? Values as a basis for pro-environmental social change actions. Frontiers in Psychology, 9, 1-10. https://doi.org/10.3389/fpsyg.2018.01229

Steg, L., \& De Groot, J.I.M. (2012). Environmental values. In S. Clayton (ed.), The Oxford handbook of environmental and conservation psychology (pp. 81-92). New York: Oxford University Press.

van der Werff, E., \& Steg, L. (2016). The psychology of participation and interest in smart energy systems: Comparing the value-belief-norm theory and the value-identity-personal norm model. Energy Research and Social Science, 22, 107-114.

https://doi.org/10.1016/j.erss.2016.08.022 
Appendix B: Means and 95\% confidence intervals for value and influence behavior items, missing data across variables

\begin{tabular}{|c|c|c|c|c|c|c|c|}
\hline \multirow{3}{*}{ 更 } & 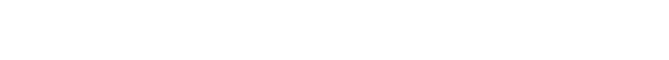 & \multicolumn{3}{|c|}{ Descriptive statistics } & \multirow{2}{*}{\multicolumn{3}{|c|}{$\begin{array}{r}\text { Missing data } \\
\text { Missing }\end{array}$}} \\
\hline & \multirow[t]{2}{*}{ Variable } & \multirow[t]{2}{*}{ Mean } & \multicolumn{2}{|c|}{ 95\% Confidence Interval } & & & \\
\hline & & & LL & UL & $\mathrm{N}$ & Count & Percent \\
\hline \multirow{16}{*}{$\frac{\stackrel{d}{ٍ}}{\stackrel{\pi}{\pi}}$} & $\begin{array}{l}\text { Altruistic (everyone has the same } \\
\text { opportunities) }\end{array}$ & 6.42 & 6.28 & 6.56 & 191 & 2 & $1.0 \%$ \\
\hline & $\begin{array}{l}\text { Biospheric (live together with plants and } \\
\text { animals) }\end{array}$ & 5.98 & 5.80 & 6.16 & 190 & 3 & $1.6 \%$ \\
\hline & Egoistic (have control over others) & 3.09 & 2.84 & 3.35 & 192 & 1 & $.5 \%$ \\
\hline & Hedonic (do things that are nice to do) & 6.01 & 5.86 & 6.16 & 187 & 6 & $3.1 \%$ \\
\hline & $\begin{array}{l}\text { Biospheric (feeling part of nature, belonging } \\
\text { to nature) }\end{array}$ & 5.13 & 4.91 & 5.34 & 190 & 3 & $1.6 \%$ \\
\hline & Altruistic (no war and fighting) & 6.14 & 5.94 & 6.33 & 189 & 4 & $2.1 \%$ \\
\hline & Egoistic (have lots of things and money) & 3.98 & 3.76 & 4.21 & 192 & 1 & $.5 \%$ \\
\hline & $\begin{array}{l}\text { Egoistic (I am in charge, tell others what to } \\
\text { do) }\end{array}$ & 2.92 & 2.68 & 3.17 & 191 & 2 & $1.0 \%$ \\
\hline & $\begin{array}{l}\text { Altruistic (everyone gets treated fairly, others } \\
\text { taken care of) }\end{array}$ & 6.19 & 6.04 & 6.34 & 190 & 3 & $1.6 \%$ \\
\hline & Hedonic (have nice meals, nice things) & 5.53 & 5.35 & 5.72 & 188 & 5 & $2.6 \%$ \\
\hline & Biospheric (environment is taken care of) & 6.12 & 5.97 & 6.27 & 192 & 1 & $.5 \%$ \\
\hline & Egoistic (influence other people and events) & 3.87 & 3.62 & 4.12 & 191 & 2 & $1.0 \%$ \\
\hline & Altruistic (make other people happy) & 6.05 & 5.90 & 6.19 & 188 & 5 & $2.6 \%$ \\
\hline & Biospheric (environment will not be polluted) & 5.94 & 5.79 & 6.09 & 190 & 3 & $1.6 \%$ \\
\hline & Hedonic (do things that I enjoy doing) & 6.11 & 5.96 & 6.25 & 189 & 4 & $2.1 \%$ \\
\hline & Egoistic (work hard, do my best) & 5.98 & 5.82 & 6.14 & 188 & 5 & $2.6 \%$ \\
\hline \multirow{8}{*}{ 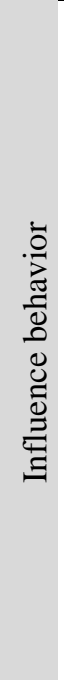 } & Turn off the lights when leaving the room & 4.83 & 4.49 & 5.16 & 155 & 38 & $19.7 \%$ \\
\hline & $\begin{array}{l}\text { To shut off electrical appliances when not in } \\
\text { use }\end{array}$ & 3.91 & 3.58 & 4.25 & 161 & 32 & $16.6 \%$ \\
\hline & $\begin{array}{l}\text { To NOT leave the fridge door open while } \\
\text { thinking about what to eat }\end{array}$ & 4.30 & 3.95 & 4.64 & 158 & 35 & $18.1 \%$ \\
\hline & To shower less than 5 minutes. & 2.34 & 2.08 & 2.59 & 180 & 13 & $6.7 \%$ \\
\hline & $\begin{array}{l}\text { To only start the washing machine when it is } \\
\text { full }\end{array}$ & 4.27 & 3.92 & 4.63 & 161 & 32 & $16.6 \%$ \\
\hline & $\begin{array}{l}\text { To NOT leave the water running while } \\
\text { brushing their teeth }\end{array}$ & 4.29 & 3.90 & 4.69 & 150 & 43 & $22.3 \%$ \\
\hline & $\begin{array}{l}\text { To reduce or turn off heating in unoccupied } \\
\text { rooms }\end{array}$ & 4.22 & 3.89 & 4.56 & 165 & 28 & $14.5 \%$ \\
\hline & $\begin{array}{l}\text { To NOT leave their mobile phone(s) on the } \\
\text { charger for the night }\end{array}$ & 1.84 & 1.61 & 2.07 & 179 & 14 & $7.3 \%$ \\
\hline
\end{tabular}

